\title{
Sustainability Investment of a Two-Echelon Supply Chain under Cap-and-Trade Regulation
}

\author{
Yuyu Chen ${ }^{1, *}$ Jianfei $\mathrm{Gu}^{2}$ \\ ${ }^{1}$ School of business, Changshu Institute of Technology, Changshu 215500, China \\ ${ }^{2}$ School of Electrical and Automatic Engineering, Changshu Institute of Technology, Changshu 215500, China \\ ${ }^{*}$ Corresponding author. Email: chenyuyu@nuaa.edu.cn
}

\begin{abstract}
Taking into account the consumer has a low carbon preference, under the dual driving force of environment production and economic benefit, the manufacturer will invest in emission reduction technology in the upstream and downstream, such as introduce emission reduction equipment or cleaner production technology. We focus on a twoechelon sustainable supply chain that includes single manufacturer and single retailer. We explore how should manufacturer rationally choose the way of investment in emission reduction, i.e., whether the manufacturer should invest in both upstream and downstream or only in the upstream. Compared with the sustainable investment only in the upstream, investment in both upstream and downstream is more sustainable and profitable.
\end{abstract}

Keywords: Cap-and-trade regulation, Sustainability investment, Stackelberg game, Consignment contract

\section{INTRODUCTION}

With the rapid economic development, global temperatures have become warmer, and the harm caused by the greenhouse effect has attracted the attention of the entire society. Various countries have successively enacted relevant laws to limit the emission of greenhouse gases. The cap-and-trade regulation is a market-based emission reduction policy, with the most significant implementation effect and successful implementation in many countries. Under this regulation, the carbon emission right is considered as a commodity that can be available for trading.

Some scholars have studied the supply chain operation decision making under the carbon regulations. Based on newsboy model, the literature [1] gets the unique Nash equilibrium strategy through game analysis of pricing and output between the manufacturer and the supplier. Using Stackelberg game theory, [2] explores the impact of carbon cap-and-trade regulation on the two-echelon supply chain system decision making involving single manufacturer and single supplier. Literature [3] analyzes the impact of different carbon policies (mandatory carbon quota, carbon tax and carbon cap-and-trade) from the perspective of manufacturer pricing and the retailer's ordering quantity.

The focus of the above study is to use different carbon emissions regulations to control carbon emissions without considering emissions reduction investments. However, in reality, companies usually introduce emissions reduction equipment or cleaner production technologies during their production or sales process, thereby increasing economic efficiency and achieving social responsibility. For example, [4] analyzes production planning decisions and green technology investment under different carbon regulatory mechanisms. [5] focuses on the choice of production technology, and discuss the impact of carbon trading policy and carbon tax policy on enterprise production decisions respectively. [6] studies the game of two sustainable supply chains with sustainable levels of product competition and derived a balanced decision for chain and chain competition. However, the above literature only focuses on the emission reduction strategies in the upstream of supply chain, ignoring their emission reduction measures in downstream, such as during transportation and sales. Therefore, this paper will fully analyze how should the manufacturer rationally choose the way of investment in emission reduction, i.e., whether the manufacturer should invest in both upstream and downstream or only in the upstream.

Coordination of supply chain considering investment in emission reduction technology. [7] studies the impact of carbon cap-and-trade regulation on 
corporate production and emission reduction strategies, and further introduce contracts to coordinate the supply chain. [8] compares and analyze the impact of the revenue-sharing and two-part tariff contracts on the coordination of two-level sustainable supply chain, and find that the latter can achieve perfect coordination. [9] studies a two-echelon supply chain consisting of single manufacturer and single supplier, and both parties are investing in emission reduction technologies, and based on the two-part tariff, the supply chain can be effectively coordinated.

Although research has been conducted on the coordination of low-carbon supply chains under the carbon regulations, However, there are few studies on the consignment contract. The consignment contract is a method in which a manufacturer consigns a product to a retailer, entrusts the retailer to sell the product to the customer, and if the product is sold, the downstream retailer determines the proportion of the income to be obtained. Today, the large retailer in today's society has more and more dominant power, such as the large supermarket, such as WAL-MART[10], so it is more practical and practical to study the retailer as the leader.

Based on the above analysis, we explore the decision of the two-echelon sustainable supply chain under the consignment contract based on the carbon cap-and-trade regulation. It is proposed that the manufacturer should choose the technology investment mode rationally under the restriction of the carbon cap-and-trade regulation.

\section{MODEL AND DECISION ANALYSIS}

This article examines a two-echelon supply chain consisting of a single manufacturer and a single retailer, where the retailer is the leader of the Steinberger game. Based on the consignment contract, the retailer is responsible for selling the product and determining the revenue share ratio $r$ in the consignment contract, and the manufacturer decides to invest in emission reduction technology only in the upstream or in both upstream and downstream, and determines the sustainability level $s_{m}$ and $s_{r}$.

Taking into account consumers' low-carbon consumption preferences and government's policy, manufacturers will invest in emission reduction technologies. The investment in emission reduction technologies in the upstream and downstream are $\frac{1}{2} c_{i m} s_{m}^{2}$ and $\frac{1}{2} c_{i r} s_{r}^{2}$, where $c_{i m}$ and $c_{i r}$ are the sustainability investment coefficients.

After reducing investment, carbon emissions of unit product are $a-b_{m} s_{m}-b_{r} s_{r}$, where $a$ represents the basic carbon emissions per unit of product, $b_{m}$ represents the coefficient of influence of upstream sustainable levels on reducing carbon emissions, and $b_{r}$ represents the impact coefficient of downstream sustainable levels on reducing carbon emissions. In particular, when sustainable investment in upstream only, carbon emissions of unit product are $a-b_{m} s_{m}$.

It is worth noting that investment in emission reduction technology not only reduces the carbon emissions of products, but also affects the market demand of consumers for the product. As the environmental awareness of the public increases, consumers are more interested in environmental protection (lower carbon emission) products, so market demand is positively correlated with the level of sustainability, that is, market demand increases with the increase of sustainable levels. In the make-to-order environment, the market demand function is $D\left(s_{m}, s_{r}\right)=D_{0}+\alpha_{m} s_{m}+\alpha_{r} s_{r}$, where $\alpha_{m}>0, \alpha_{r}>0$. In particular, when sustainable investment in upstream only, the market demand function is $D\left(s_{m 1}\right)=D_{0}+\alpha_{m} s_{m}$.

Under the carbon cap-and-trade regulation, the government set the carbon cap $K$ firstly, if the total carbon emissions exceed the carbon cap $K$, the producer will purchase excess carbon emission rights at unit price a $c_{e}$. Otherwise, if the total carbon emission is less than the carbon cap, the producer will sell it at the same price in the carbon trading market.

\subsection{Sustainable investment in upstream only}

In a decentralized decision system under a consignment contract, manufacturers sell products to customers through retailers. As the leader of Steinberger's game, retailers first determine the proportion of revenue sharing $1-r_{1}$. After the goods are sold, the retailer will return $r_{1}$ of the profit to the manufacturer. As the Steinberger game follower, the manufacturer will determine the level of sustainability based on the retailer's determination, thereby maximizing its profit. For the sake of distinction, the subscript " 1 " is added to the variables for upstream emission reduction technology investment only. Under the consignment contract, the manufacturer's profit is

$$
\begin{aligned}
\Pi_{M 1}\left(s_{m 1}\right) & =r_{1} p D\left(s_{m 1}\right)-c_{m} D\left(s_{m 1}\right) \\
& -c_{e}\left[\left(a-b_{m} s_{m 1}\right) D\left(s_{m 1}\right)-K\right]-\frac{1}{2} c_{i m} s_{m 1}^{2}
\end{aligned}
$$

In the above function, the first part represents the shared income provided by the retailer, the second part represents the production cost, the third part is the revenue or cost of the carbon emissions trading, and the last part represents the investment cost of the emission reduction technology. As the leader of the Steinberger game, the profit of the retailer is

$$
\Pi_{R 1}\left(r_{1}\right)=\left(1-r_{1}\right) p\left(D_{0}+\alpha_{m} s_{m 1}\right)
$$

Theorem 1 When implement the sustainable 
investment in the upstream only, the market demand function is $D\left(s_{m 1}\right)=D_{0}+\alpha s_{m 1}$, The optimal revenue sharing ratio, $r_{1}^{*}$, determined by the retailer under the consignment contract is

$$
r_{1}^{*}=\frac{\alpha_{m}^{2}\left(p+c_{m}+c_{e} a\right)-\left(c_{i m}-c_{e} b_{m} \alpha_{m}\right) D_{0}}{2 \alpha^{2} p}
$$

The optimal sustainable level $s_{m 1}^{*}$ determined by the manufacturer is

$$
s_{m 1}^{*}=\frac{\left(3 c_{e} b_{m} \alpha_{m}-c_{i m}\right) D_{0}+\alpha_{m}^{2}\left(p-c_{m}-c_{e} a\right)}{2 \alpha\left(c_{i m}-2 c_{e} b_{m} \alpha_{m}\right)}
$$

Substituting equations (3) and (4) into (1) and (2), we can get the manufacturer's optimal profit $\Pi_{M 1}^{*}\left(s_{d 1}^{*}\right)$ and retailer's optimal profit $\Pi_{R 1}^{*}\left(r_{1}^{*}\right)$ are

$$
\begin{gathered}
\Pi_{M 1}^{*}\left(s_{m 1}^{*}\right)=\frac{\left\{\begin{array}{l}
{\left[c_{e}^{2} b_{m}^{2} \alpha_{m}^{2}-3 c_{i m}\left(c_{i m}-2 c_{e} b_{m} \alpha_{m}\right)\right] D_{0}^{2}} \\
+\alpha_{m}^{4}\left(p-c_{m}-c_{e} a\right)^{2} \\
+2 \alpha_{m}^{2}\left(c_{i}-c_{e} b_{m} \alpha_{m}\right) D_{0}\left(p-c_{m}-c_{e} a\right)
\end{array}\right\}}{8 \alpha_{m}^{2}\left(c_{i m}-2 c_{e} b_{m} \alpha_{m}\right)}+c_{e} K \\
\Pi_{R 1}^{*}\left(r_{1}^{*}\right)=\frac{\left\{\begin{array}{l}
\left(c_{i m}-c_{e} b_{m} \alpha_{m}\right)^{2} D_{0}^{2}+\alpha_{m}^{4}\left(p-c_{m}-c_{e} a\right)^{2} \\
+2 \alpha_{m}^{2}\left(c_{i m}-c_{e} b_{m} \alpha_{m}\right) D_{0}\left(p-c_{m}-c_{e} a\right)
\end{array}\right\}}{4 \alpha^{2}\left(c_{i m}-2 c_{e} b_{m} \alpha_{m}\right)} .
\end{gathered}
$$

\subsection{Sustainable investment in both upstream and downstream}

As the follower of the Steinberger game, the manufacturer's profit is

$$
\begin{aligned}
\Pi_{M 2}\left(s_{m}, s_{r}\right) & =\left(r_{2} p-c_{m}\right) D\left(s_{m}, s_{r}\right) \\
& -c_{e}\left[\left(a-b_{m} s_{m}-b_{r} s_{r}\right) D\left(s_{m}, s_{r}\right)-K\right] \\
& -\frac{1}{2} c_{i m} s_{m}^{2}-\frac{1}{2} c_{i r} s_{r}^{2}
\end{aligned}
$$

In the above function, the first part represents the economic benefits of production decisions. The second part represents the benefits or costs of carbon emissions trading. The last two parts are the sustainable investment costs in the upstream and downstream respectively.

As the leader of the Steinberger game, the profit of the retailer is

$$
\Pi_{R 2}\left(r_{2}\right)=\left(1-r_{2}\right) p D\left(s_{m}, s_{r}\right)
$$

To

$$
\text { simplify the presentation, }
$$

we redefine

$$
\tau_{1}=c_{e}\left(c_{i r} b_{m}-c_{e} b_{m} b_{r} \alpha_{r}+c_{e} b_{r}^{2} \alpha_{m}\right)
$$

$\tau_{2}=c_{i r} \alpha_{m}-c_{e} b_{r} \alpha_{m} \alpha_{r}+c_{e} b_{m} \alpha_{r}^{2}$

$\tau_{3}=c_{e}\left(c_{i m} b_{r}-c_{e} b_{m} b_{r} \alpha_{m}+c_{e} b_{m}^{2} \alpha_{r}\right)$

$\tau_{4}=c_{i m} \alpha_{r}-c_{e} b_{m} \alpha_{m} \alpha_{r}+c_{e} b_{r} \alpha_{m}^{2}$

$\tau_{5}=c_{i m} c_{i r}-c_{i m} c_{e} b_{r} \alpha_{r}-c_{i r} c_{e} b_{m} \alpha_{m}$

$\Lambda=\left(c_{i r}-2 c_{e} b_{r} \alpha_{r}\right)\left(c_{i m}-2 c_{e} b_{m} \alpha_{m}\right)-c_{e}^{2}\left(b_{m} \alpha_{r}+b_{r} \alpha_{m}\right)^{2}$.
Theorem 2 When sustainable investments are made both upstream and downstream, (1) As the leader of the Steinberger game, in order to maximize his profit, the optimal share ratio determined by the retailer $r_{2}^{*}$ is

$$
r_{2}^{*}=\frac{\left(c_{i m} \alpha_{r}^{2}+c_{i r} \alpha_{m}^{2}\right)\left(p+c_{m}+c_{e} a\right)-\tau_{5} D_{0}}{2\left(c_{i m} \alpha_{r}^{2}+c_{i r} \alpha_{m}^{2}\right) p}
$$

(2) To maximize his profit, optimal sustainable levels $s_{m}^{*}$ and $s_{r}^{*}$ determined by the manufacturer are

$$
\begin{gathered}
\left\{\begin{array}{l}
{\left[2\left(c_{i m} \alpha_{r}^{2}+c_{i r} \alpha_{m}^{2}\right) \tau_{1}-\tau_{5} \tau_{2}\right] D_{0}} \\
+\left(c_{i m} \alpha_{r}^{2}+c_{i r} \alpha_{m}^{2}\right) \tau_{2}\left(p-c_{m}-c_{e} a\right)
\end{array}\right\} \\
2\left(c_{i m} \alpha_{r}^{2}+c_{i r} \alpha_{m}^{2}\right) \Lambda \\
s_{m}^{*}=\frac{\left\{\begin{array}{l}
{\left[2\left(c_{i m} \alpha_{r}^{2}+c_{i r} \alpha_{m}^{2}\right) \tau_{3}-\tau_{5} \tau_{4}\right] D_{0}} \\
+\left(c_{i m} \alpha_{r}^{2}+c_{i r} \alpha_{m}^{2}\right) \tau_{4}\left(p-c_{m}-c_{e} a\right)
\end{array}\right\}}{2\left(c_{i m} \alpha_{r}^{2}+c_{i r} \alpha_{m}^{2}\right) \Lambda} .
\end{gathered}
$$

Substituting equations (7), (8), and (9) into (5) and (6) yields the manufacturer's optimal profit is

$$
\begin{aligned}
\Pi_{M 2}^{*}\left(s_{m}^{*}, s_{r}^{*}\right) & =\frac{\left\{\begin{array}{l}
4 c_{e}^{2}\left(c_{i m} b_{r}^{2}+c_{i r} b_{m}^{2}\right) D_{0}^{2} \\
+\left(c_{i m} \alpha_{r}^{2}+c_{i r} \alpha_{m}^{2}\right)\left(p-c_{m}-c_{e} a\right)^{2} \\
+2 \tau_{5} D_{0}\left(p-c_{m}-c_{e} a\right)
\end{array}\right\}}{8 \Lambda}, \\
& -\frac{3 \tau_{5}^{2} D_{0}^{2}}{8\left(c_{i m} \alpha_{r}^{2}+c_{i r} \alpha_{m}^{2}\right) \Lambda}+c_{e} K
\end{aligned}
$$

The retailer's optimal profit is

$$
\begin{aligned}
\Pi_{R 2}^{*}\left(r_{2}^{*}\right) & =\frac{\left\{\begin{array}{l}
\left(c_{i m} \alpha_{r}^{2}+c_{i r} \alpha_{m}^{2}\right)\left(p-c_{m}-c_{e} a\right)^{2} \\
+2 \tau_{5} D_{0}\left(p-c_{m}-c_{e} a\right)
\end{array}\right\}}{4 \Lambda} \\
& +\frac{\tau_{5}^{2} D_{0}^{2}}{4\left(c_{i m} \alpha_{r}^{2}+c_{i r} \alpha_{m}^{2}\right) \Lambda}
\end{aligned}
$$

\subsection{Comparison and analysis}

Theorem 3 When $\alpha_{m}=\alpha_{r}=\alpha, b_{m}=b_{r}=b$ and $c_{i m}=c_{i r}=c_{i}$, (1) The optimal sustainable level of sustainable investment in both upstream and downstream is higher than the sustainable level of sustainable investment in the upstream only,

$$
s_{m}^{*}+s_{r}^{*}-s_{m 1}^{*}=\frac{c_{i} c_{e} b D_{0}+2 c_{e} b \alpha^{2}\left(p-c_{m}-c_{e} a\right)}{2\left(c_{i}-4 c_{e} b \alpha\right)\left(c_{i}-2 c_{e} b \alpha\right)}>0
$$

(2) Compare with sustainable investment in the upstream only, the total profit of the supply chain is higher when sustainably investing in both upstream and downstream, 


$$
\begin{aligned}
\Pi_{2}^{*}\left(s_{m}^{*}, s_{r}^{*}\right)-\Pi_{1}^{*}\left(s_{m 1}^{*}\right) & =\frac{\left\{\begin{array}{l}
3 c_{i}\left(c_{e}^{2} b^{2} D_{0}^{2}+\alpha^{2}\left(p-c_{m}-c_{e} a\right)^{2}\right. \\
\left.+2 c_{e} b \alpha D_{0}\left(p-c_{m}-c_{e} a\right)\right)
\end{array}\right\}}{8\left(c_{i}-2 c_{e} b \alpha\right)\left(c_{i}-4 c_{e} b \alpha\right)} \\
& +\frac{c_{i} D_{0}^{2}}{16 \alpha^{2}}>0
\end{aligned}
$$

(3) Compare with sustainable investment in the upstream only, the profit of the manufacturer is higher when sustainably investing in both upstream and downstream,

$$
\begin{aligned}
\Pi_{M 2}^{*}\left(s_{m}^{*}, s_{r}^{*}\right)-\Pi_{M 1}^{*}\left(s_{m 1}^{*}\right)=\frac{3 c_{i} D_{0}^{2}}{16 \alpha^{2}} \\
+\frac{\left\{\begin{array}{l}
c_{i}\left(c_{e}^{2} b^{2} D_{0}^{2}+\alpha^{2}\left(p-c_{m}-c_{e} a\right)^{2}\right. \\
\left.+2 c_{e} b \alpha D_{0}\left(p-c_{m}-c_{e} a\right)\right)
\end{array}\right\}}{8\left(c_{i}-2 c_{e} b \alpha\right)\left(c_{i}-4 c_{e} b \alpha\right)}>0
\end{aligned}
$$

Theorem 3 shows that sustainable investment by the manufacturer in both upstream and downstream can reduce the impact of the environment and increase the total profit of the supply chain. In addition, it can also increase the profit of the manufacturer. Therefore, the manufacturer should invest in emission reduction technologies both upstream and downstream.

\section{NUMERICAL STUDY}

The definition of $\Delta_{\Pi 1}$ and $\Delta_{\Pi 2}$ are the profit loss rates of the model investing in upstream only and the model investing in both upstream and downstream, respectively. Figure 1 shows that with the increase of $\mathrm{c}$ carbon cap $K$, the profit loss rate $\Delta_{\Pi 1}$ and $\Delta_{\Pi 2}$ decrease, that is, only when the carbon cap $K$ is higher, the profit loss under consignment contract is smaller, Especially, when the manufacturer makes emission reduction investment in both upstream and downstream, if the carbon limit is greater than 470 , the profit loss rate $\Delta_{\Pi 2}$ is below $25 \%$. When the manufacturer makes emission reduction investment in upstream only, if the carbon limit is greater than 940 , the profit loss rate $\Delta_{\Pi 1}$ is below $25 \%$.

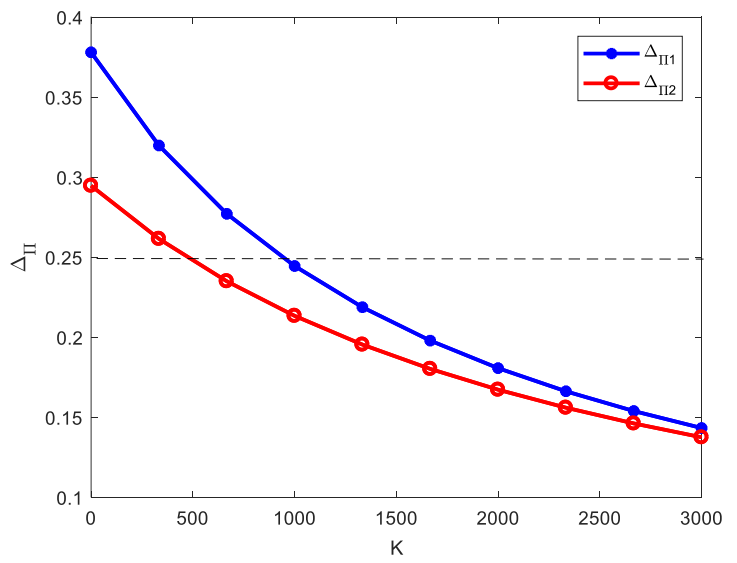

On the other hand, for a fixed carbon cap $K$, the profit loss rate of the model investing in both upstream and downstream (i.e., $\Delta_{\Pi 2}$ ) is less than the model investing in upstream only (i.e., $\Delta_{\Pi 1}$ ). Therefore, the consignment contract is more suitable for supply chain coordination when sustainable investment is made in production and sales in both upstream and downstream.

\section{CONCLUSION}

Based on the carbon cap-and-trade regulation, we consider the low carbon preference and emission reduction technology investment, and study the consignment contract for the downstream retailer of the two-echelon supply chain (the leader of the Stackelberg game) to determine the proportion of revenue sharing in the consignment contract. The upstream manufacturer (the follower of the Stackelberg game) decides on the mode of investment in emission reduction technologies and determine the level of emission reductions. Through comparison with the investment in emission reduction technology only in the upstream, it was found that the investment in emission reduction technology in both the upstream and downstream areas not only has a high level of emission reduction (i.e., is more environmentally friendly), but also increases both the total system profits and the profits of manufacturers.

This paper has certain guiding significance for the manufacturers to reduce the emission reduction under the restriction of the quota and transaction mechanism, and is of certain reference value for the development of low carbon economy.

\section{ACKNOWLEDGMENTS}

The work in this paper was supported by the National Natural Science Foundation, China (No. 71771138, 71702087), the Humanities and Social Sciences Youth Foundation of Ministry of Education, China (No. 17YJC630004).

\section{REFERENCES}

[1] S. Du, F. Ma, Z. Fu, L. Zhu and J. Zhang, Gametheoretic analysis for an emission-dependent supply chain in a 'cap-and-trade' system, Annals of Operations Research, 228 (2015), pp. 135-149.

[2] S. Du, L. Zhu, L. Liang and F. Ma, Emissiondependent supply chain and environment-policymaking in the 'cap-and-trade' system, Energy Policy, 57 (2013), pp. 61-67.

[3] Y. Zheng, X. Yang and Z. Wang, Manufacture's optimal pricing policy and retailer's optimal ordering policy under different carbon emission policies, Progress in Applied Mathematics, 7 (2014), pp. 20-26.

[4] A. E. Toptal, H. I. Zlü and D. E. Konur, Joint 
decisions on inventory replenishment and emission reduction investment under different emission regulations, International Journal of Production Research, 52 (2014), pp. 243 - 269.

[5] D. F. Drake, P. R. Kleindorfer and L. N. Van Wassenhove, Technology choice and capacity portfolios under emissions regulation, Production and Operations Management, 25 (2016), pp. 10061025.

[6] X. Li and Y. Li, Chain-to-chain competition on product sustainability, Journal of Cleaner Production, 112 (2016), pp. 2058-2065.

[7] C. Dong, B. Shen, P. Chow, L. Yang and C. T. Ng, Sustainability investment under cap-and-trade regulation, Annals of Operations Research, 240 (2016), pp. 509-531.

[8] J. $\mathrm{Xu}, \mathrm{Y}$. Chen and Q. Bai, A two-echelon sustainable supply chain coordination under capand-trade regulation, Journal of Cleaner Production, 135 (2016), pp. 42-56.

[9] S. Swami and J. Shah, Channel coordination in green supply chain management, Journal of the Operational Research Society, 64 (2013), pp. 336351.

[10] F. L. Yun, Y. Wang and Y. Wu, Consignment Contracts with Revenue Sharing for A Capacitated Retailer and Multiple Manufacturers, Manufacturing \& Service Operations Management, 17 (2016), pp. 527-537. 